\title{
RESEARCH
}

\section{Identification of a Novel Paternally Expressed Transcript Adjacent to snRPN in the Prader-Willi Syndrome Critical Region}

\author{
Yi Ning, ${ }^{1}$ Anna Roschke, ${ }^{1}$ Susan L. Christian, ${ }^{1}$ Jennifer Lesser, ${ }^{1}$ \\ James S. Sutcliffe, ${ }^{2}$ and David H. Ledbetter ${ }^{1,3}$
}

\author{
'Diagnostic Development Branch, National Center for Human Genome Research, National Institutes of \\ Health, Bethesda, Maryland 20892; ${ }^{2}$ Department of Molecular and Human Genetics, Baylor College of \\ Medicine, Houston, Texas 77030
}

\begin{abstract}
Small nuclear ribonucleoprotein-associated polypeptide $\mathrm{N}$ (snRPN) and an anonymous transcript, PAR-5, are two of the paternally expressed transcripts mapped to the Prader-Willi syndrome critical region. Using long-range PCR, we have isolated the genomic interval between snRPN and PAR-5, identified a novel transcript in this region, and termed it PAR-SN. Northern analysis demonstrates that PAR-SN is expressed in brain, skeletal muscle, and heart. Like snRPN and PAR-5, PAR-SN is expressed exclusively from the paternal homolog in cultured lymphoblasts. Sequence analysis of the transcript revealed no significant open reading frame but did include a polymorphic dinucleotide repeat $(C A)_{17}$.
\end{abstract}

Prader-Willi syndrome (PWS) and Angelman syndrome (AS) are two distinct mental retardation syndromes caused by paternal and maternal deficiencies, respectively, in chromosome 15q11-q13. PWS is characterized by infantile hypotonia, growth and mental retardation, and hyperphagia with subsequent obesity. Characteristic facial appearance and other physical features are also observed (Holm et al. 1993). Approximately $70 \%$ of PWS cases are caused by a paternal deletion of chromosome 15q11-q13, whereas most of the remaining cases have maternal uniparental disomy (Nicholls et al. 1989; Butler et al. 1990; Robinson et al. 1991; Mascari et al. 1992). These findings indicate that a deficiency of paternally expressed genes gives rise to the PWS phenotype. The gene encoding the small nuclear ribonucleoprotein-associated polypeptide $\mathrm{N}$ (snRPN) was identified as a candidate gene for PWS based on mapping to the PWS critical region and paternal expression in the mouse (Cattanach et al. 1992; Leff et al. 1992; Ozcelik et al. 1992) and human (Nakao et al. 1994; Reed and Leff 1994). Recently, three paternally expressed transcripts, PAR-1, PAR-5, and imprinted in Prader-Willi (IPW) (Wevrick et al. 1994), have also been iden-

${ }^{3}$ Corresponding author.

E-MAIL: dhi@babies.bsd.uchicago.edu; FAX: (312) 834-0505. tified in the critical region (Sutcliffe et al. 1994; Wevrick et al. 1994). These transcripts are located within $300 \mathrm{~kb}$ telomeric to snRPN, defining a large imprinted transcriptional domain. The expression of the imprinted transcripts was found to correlate with maternal-specific DNA methylation at the snRPN CpG island, which includes the first exon $(\alpha)$ of the gene (Sutcliffe et al. 1994; Glenn et al. 1996) and PW71 (D15S63) (Reis et al. 1994; Dittrich et al. 1992). Small deletions encompassing the differentially methylated $\mathrm{CpG}$ island and upstream region abolished expression of snRPN, PAR-1, and PAR-5 in rare PWS imprinting mutation patients (Sutcliffe et al. 1994) and identified the putative $15 q$ imprinting center, which appears to act by controlling appropriate methylation and imprinting patterns in the PWS/AS region (Sutcliffe et al. 1994; Buiting et al. 1995). The existence of a large imprinted domain extending over hundreds of kilobases suggests that multiple genes in this region could be involved in the pathophysiology of PWS.

To improve our understanding of the imprinted region and to define the breakpoints of small deletions in imprinting-mutation patients with PWS, we used a long-range PCR approach to amplify a region between snRPN and PAR-5, which was uncloned in the previously reported cosmid contig (Sutcliffe et al. 1994). According to 
the size of the PCR product, we estimated the distance between snRPN and PAR- 5 to be $\sim 7 \mathrm{~kb}$. Expression analysis revealed a novel paternally expressed transcript, PAR-SN. Sequence analysis of this region identified a polymorphic dinucleotide repeat $(\mathrm{CA})_{17}$ within the $7-\mathrm{kb}$ interval.

\section{RESULTS}

\section{PCR Product between snRPN and PAR-5}

A cosmid contig representing a subset of the common deletion region in PWS patients was established to facilitate molecular studies of the syndrome (Sutcliffe et al. 1994). Pulsed-field mapping and hybridization of cDNAs to the cosmid contig positioned PAR-5 as the nearest transcript distal to snRPN (Sutcliffe et al. 1994). PAR-5 detects a large $(-12 \mathrm{~kb})$ transcript prominent in skeletal muscle, although sequence analysis of $3.1 \mathrm{~kb}$ from this transcript (GenBank accession no. L78267) reveals no significant open reading frame (ORF) and colinearity with genomic DNA (Sutcliffe et al. 1994). As there existed a small cloning gap between the cosmids containing snRPN and PAR-5, we adopted a long-range PCR approach to amplify and clone the intervening region. Using the sequence from the snRPN $3^{\prime}-$ untranslated region (GenBank accession no. $\mathrm{X} 15892$ ) and the sequence of PAR-5 (GenBank accession no. L78267), we amplified the region from snRPN to PAR-5 and determined the distance between the two to be $\sim 7 \mathrm{~kb}$.

\section{Identification of a Novel Paternally Expressed Transcript}

The 7-kb PCR product was hybridized to a multiple-tissue Northern blot. In addition to the expected transcripts of 1.3 and $-12 \mathrm{~kb}$ corresponding to snRPN and PAR-5, respectively, we detected an additional transcript of $3 \mathrm{~kb}$. To further characterize the $3-\mathrm{kb}$ transcript, we cloned the 7-kb PCR product into three $X b a \mathrm{I}$ fragments of $1.7,4.3$, and $0.8 \mathrm{~kb}$ (Fig. 1). Northern blot analysis with the three fragments demonstrated separately that the $1.7-\mathrm{kb}$ probe detected only the snRPN transcript, whereas the $4.3-\mathrm{kb}$ probe detected the 3-kb transcript. As shown in Figure 2, PAR-SN is predominantly expressed in brain, skeletal muscle, and heart. The $4.3-\mathrm{kb}$ probe was then used to screen a skeletal muscle cDNA library leading to the isolation of a partial cDNA clone of $1.1 \mathrm{~kb}$.

After sequencing the partial cDNA clone, we used $5^{\prime}$ and $3^{\prime}$ rapid amplification of cDNA ends (RACE) to extend the cDNA sequence. The $5^{\prime}$ RACE resulted in a $0.8-\mathrm{kb}$ fragment, but the $3^{\prime}$ RACE was unsuccessful after several attempts. To obtain additional cDNA sequence at the $3^{\prime}$ region, we designed primers from the cDNA and genomic sequences (Fig. 1) to amplify cDNAs from the muscle library. The $5^{\prime}$ RACE product and the $3^{\prime}$ PCR product were labeled and hybridized separately to Northern blots to confirm that all of the amplified fragments detected the $3-\mathrm{kb}$ transcript. Sequence comparison of the genomic DNA to the cDNA clone, the 5' RACE product, and the PCR-amplified $3^{\prime}$ cDNA showed that like PAR-1 and PAR-5, all of the sequences of the cDNA are colinear with genomic sequences. According to the sequence from the $5^{\prime}$ RACE, we determined that the $5^{\prime}$ boundary of PAR-SN is at bp 117 of the genomic sequence (GenBank accession no. U55937). Although we do not have the $3^{\prime}$ end of the transcript, complete genomic sequence of the $0.8-\mathrm{kb} \mathrm{Xbal}$ fragment overlaps the PAR-5 sequence. All of the cDNA sequences together resulted in a total of $3.2 \mathrm{~kb}$. As the novel transcript is $\sim 3 \mathrm{~kb}$, and a PAR-5 cDNA did not detect the 3-kb transcript (Sutcliffe et al. 1994), we predict that the $3^{\prime}$ end of the cDNA does not go beyond the $0.8-\mathrm{kb}$ region. Nucleic acid and protein data base searches of the cDNA sequence identified no significant similarity to known sequences and did not reveal any significant ORFs.

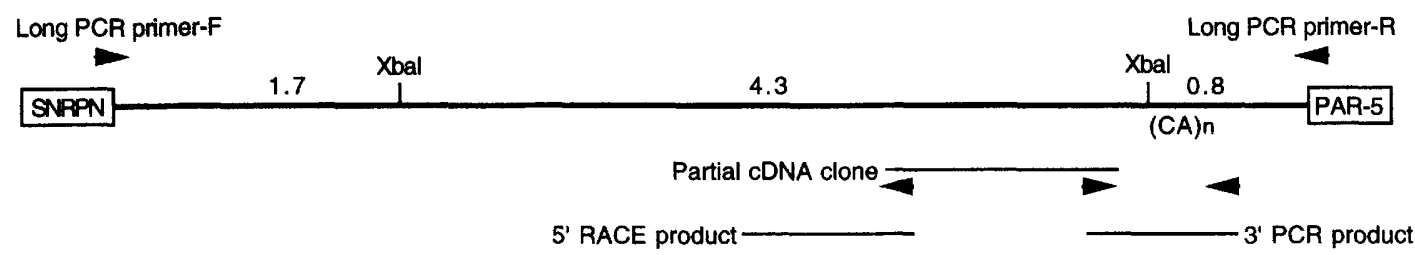

Figure 1 Genomic interval between snRPN and PAR-5. The genomic region contains three $X b a l$ fragments as indicated. Lines below represent CDNA clones or fragments. Primers that were used for long-range PCR, $5^{\prime}$ RACE, and 3' PCR of a CDNA library are indicated by arrows. 
NING ET AL.

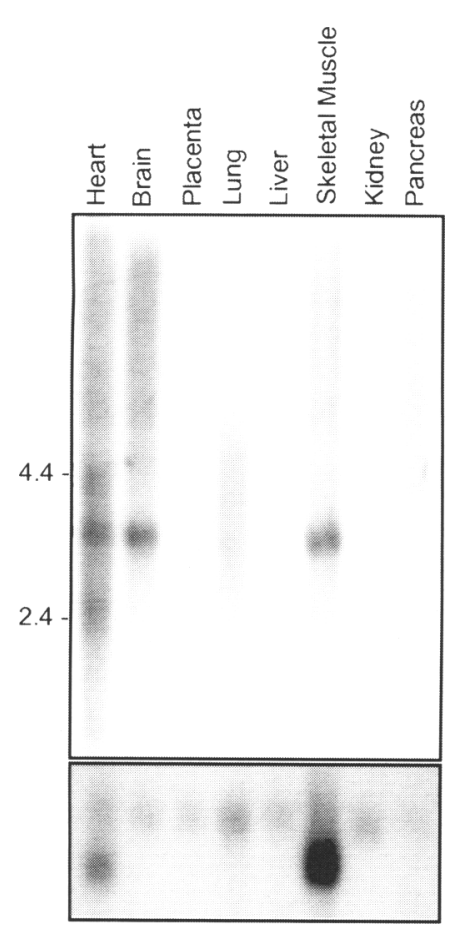

Figure 2 (Top) Tissue distribution of PAR-SN expression. A probe corresponding to the $4.3-\mathrm{kb} X \mathrm{Xbal}$ fragment was hybridized to a Northern filter containing $2 \mu \mathrm{g}$ of mRNA per lane. Positive signals are seen for heart, brain, and skeletal muscle. (Bottom) A $\beta$-actin control probe was used to show the amount of RNA loaded.

To determine the imprinting status of PAR$\mathrm{SN}$, we performed reverse transcription-coupled PCR (RT-PCR) using total RNA from cultured lymphoblast cells of PWS and AS patients with cytogenetic deletions at 15q11-q13. Because typical PWS and AS deletion patients are hemizygous for chromosome 15q11-q13, they provide a unique system to study the expression of genes in this region from maternal and paternal alleles, respectively (Nakao et al. 1994). Figure 3 demonstrates that the expression of PAR-SN was observed in a normal individual and in three unrelated AS deletion patients, but not in three PWS deletion patients. G3PDH was used as a control and was positive in all reverse-transcribed samples. These data indicate that PAR-SN is imprinted with exclusive expression from the paternal allele.

\section{A Microsatellite between snRPN and PAR-5}

Sequence analysis of the $0.8-\mathrm{kb} X b a \mathrm{I}$ fragment (Fig. 1) revealed the presence of a dinucleotide repeat $(\mathrm{CA})_{17}$. Analysis of 44 chromosomes demonstrated a heterozygosity value of $73 \%$. As the cDNA sequence of PAR-SN is colinear with genomic DNA and the 3' amplified cDNA fragment detected the $3-\mathrm{kb}$ transcript, we determined that this repeat is present in the 3 ' region of the PARSN transcript. Similarly, a (CA) ${ }_{14}$ repeat was identified in the mature IPW message (Wevrick et al. 1994), although it was found to be nonpolymorphic.

\section{DISCUSSION}

A novel transcript, termed PAR-SN, was identified from the $7-\mathrm{kb}$ region between snRPN and PAR-5 and found to be located $\sim 2 \mathrm{~kb}$ distal from snRPN. PAR-SN is expressed most prominently in brain, skeletal muscle, and heart. Like snRPN, PAR-1, PAR-5, and IPW, PAR-SN is expressed exclusively from the paternal chromosome, supporting the hypothesis that all of the transcripts in the large imprinted domain are expressed monoallelically. Also like PAR-1 and PAR-5, sequence analysis of PAR-SN showed no significant ORFs and continuity with genomic DNA. Hurst et al. (1996) recently reviewed data on all known imprinted genes in mouse and human, noting that they have few and small introns.

Although the functional nature of the PAR transcripts, IPW and PAR-SN, remains unclear, possible cis-acting regulation has been proposed based on their structure and imprinting similari-

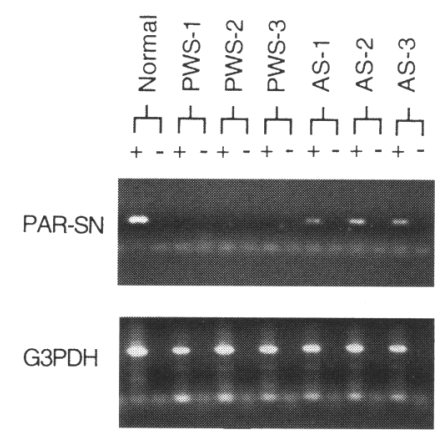

Figure 3 Imprinting analysis in cultured lymphoblasts. RT-PCR analysis was performed for PAR-SN and a control gene G3PDH, using RNA from cultured lymphoblasts of a normal individual, three PWS patients, and three AS patients with deletions at $15 q 11-q 13$ in the presence $(+)$ or absence $(-)$ of reverse transcriptase. Positive products are seen in the normal control and AS patients, but no expression is evident in the three PWS patients. 


\section{PATERNALLY EXPRESSED IRANSCRIPT}

ties to H19 and XIST (Wevrick et al. 1994). The existence of a large imprinted transcriptional domain and the paternal-specific expression pattern suggest that genes and transcripts within the domain are likely to be directly or cooperatively involved in the development of the PWS phenotype.

Sequence analysis of the genomic region and the 3 ' end of PAR-SN has led to the identification of a dinucleotide repeat polymorphism. This new marker may contribute to the molecular characterization and diagnosis of PWS, particularly for those with small deletions.

\section{METHODS}

\section{Long-range PCR}

The PCR amplification of the region between snRPN and PAR-5 was performed using an XL-PCR kit (Perkin Elmer) according to the manufacturer's recommendations. Sequences from the $3^{\prime}$ end of snRPN and $5^{\prime}$ end of PAR-5 were used to design primer pairs. Four different primer combinations were attempted to amplify DNA from a mouse-human hybrid line containing a single human chromosome 15 [National Institute of General Medical Sciences (NIGMS) human genetic mutant cell repository, GM11715]. Only the combination of snRPN forward primer (CGTCCACCAAGACCTTAGCATACTGT) and PAR-5 reverse primer (AAGTGCTTGAATGCAAGAGGCG) resulted in a $7-\mathrm{kb}$ product. This combination was repeated on total human genomic DNA, and the same result was obtained.

\section{Cloning of the Long-range PCR Product}

The $7-\mathrm{kb}$ PCR product representing the genomic region between snRPN and PAR-5 was digested with different enzymes. XbaI digestion resulted in three fragments $(0.8,1.7$, and $4.3 \mathrm{~kb})$. These fragments were isolated from a $1 \%$ agarose gel, purified, and ligated to $\mathrm{Xbal}$-digested plasmid vector pBluescriptII. Transformation was followed using host cell XL1-Blue (Stratagene). Recombinant colonies were isolated, and each was confirmed to contain the appropriate insert.

\section{Northern Analysis}

A multiple tissue Northern blot (Clontech) containing 2 $\mu \mathrm{g}$ of mRNA per lane was hybridized to the 7-kb PCR product. To further define the genomic sequences that correspond to the transcripts of snRPN, PAR-SN, and PAR-5, Northern analysis was repeated using the three cloned $X b a I$ fragments individually. Hybridization and washing were performed according to manufacturer's recommendations.

\section{CDNA Library Screening and RACE}

A skeletal muscle cDNA library (Stratagene, cat. no. 936215) was screened with the 4.3-kb XbaI fragment using standard plaque lift hybridization. Plasmids were excised from the plaque-purified phage in vivo according to manufacturer's recommendations. 5' and 3' RACE were performed using human brain Marathon-Ready cDNA (Clontech) as template. A Quick-screen human cDNA library panel (Clontech) was also utilized for obtaining the $3^{\prime}$ region of PAR-SN.

\section{DNA Sequencing}

The cloned 4.3- and 0.8-kb XbaI fragments, a partial PARSN cDNA clone, 5' RACE product, and 3' cDNA of PAR-SN were sequenced with universal or reverse vector primers or custom primers. Sequencing was performed by SeqWright (Houston, TX). Sequences corresponding to PAR-SN (5' end of PAR-SN to the beginning part of PAR- 5 CDNA) have been deposited in GenBank (under accession no. U55937).

\section{RT-PCR Analysis of Gene Expression}

Total cellular RNA was extracted from cultured human lymphoblasts of normal control, PWS, and AS deletion patients using an RNA isolation kit (Qiagen). First-strand cDNA was synthesized using $1 \mu \mathrm{g}$ of total RNA, and $\sim 100$ ng of the cDNA was used as PCR template. The cDNA was amplified with PAR-SN forward primer 5'TGAGCTCAAACGATCCTTTC and reverse primer $5^{\prime}$ TTAACAACAACCAAATAACCC, with the product size of $444 \mathrm{bp}$. PCR was for 35 cycles with 1 min each at $94^{\circ} \mathrm{C}$ and $60^{\circ} \mathrm{C}$, and $2 \mathrm{~min}$ at $72^{\circ} \mathrm{C}$. The RT-PCR control gene was G3PDH. Primers and RT-PCR conditions were provided by the manufacturer (Clontech).

\section{Microsatellite PCR Analysis}

Primer labeling, PCR reactions, and gel analysis of microsatellite were performed as described (Christian et al. 1995). Briefly, one primer was end labeled with $\left[\gamma^{32}\right.$ P]ATP using T4 polynucleotide kinase. Genomic DNA from unrelated individuals was used as PCR template and amplified with forward primer 5'-CAGTTCTTTGGACAGTTTGC and reverse primer 5'-AGGCTGGACTTCAGAGTAATCA, with a product size of $\sim 453 \mathrm{bp}$. PCR was performed in a Perkin-Elmer 9600 thermocycler with initial denaturation at $95^{\circ} \mathrm{C}$ for $4 \mathrm{~min}$, followed by 30 cycles with $30 \mathrm{sec}$ at $94^{\circ} \mathrm{C}, 30 \mathrm{sec}$ at $55^{\circ} \mathrm{C}, 30 \mathrm{sec}$ at $72^{\circ} \mathrm{C}$, and a final extension at $72^{\circ} \mathrm{C}$ for $5 \mathrm{~min}$. The PCR products were separated on a $6 \%$ acrylamide $/ 5.6 \mathrm{M}$ urea $/ 32 \%$ formamide $45-\mathrm{cm}$ gel and visualized by autoradiography.

\section{ACKNOWLEDGMENTS}

The sequence data described in this paper have been submitted to the GenBank data library under accession numbers X15892, L78267, and U55937.

The publication costs of this article were defrayed in part by payment of page charges. This article must therefore be hereby marked "advertisement" in accordance with 18 USC section 1734 solely to indicate this fact. 


\section{NING ET AL.}

\section{REFERENCES}

Buiting, K., S. Saitoh, S. Gross, B. Dittrich, S. Schwartz, R.D. Nicholls, and B. Horsthemke. 1995. Inherited microdeletions in the Angelman and Prader-Willi syndromes define an imprinting centre on human chromosome 15. Nature Genet. 9: 395-400.

Butler, M.G. 1990. Prader-Willi syndrome: Current understanding of cause and diagnosis. Am. J. Med. Genet. 35: $319-332$.

Cattanach, B.M., J.A. Barr, E.P. Evans, M. Burtenshaw, C.V. Beechey, S.E. Leff, C.I. Brannan, N.G. Copeland, N.A. Jenkins, and J. Jones. 1992. A candidate mouse model for Prader-Willi syndrome which shows an absence of Snrpn expression. Nature Genet. 2: 270-274.

Christian, S.L., W.P. Robinson, B. Huang, A. Mutirangura, M.R. Line, M. Nakao, U. Surti, A. Chakravarti, and D.H. Ledbetter. 1995. Molecular characterization of two proximal deletion breakpoints in both Prader-Willi and Angelman syndrome patients. Am. J. Hum. Genet. 57: 40-48.

Dittrich, B., W.P. Robinson, H. Knoblauch, K. Buiting, K. Schmidt, G. Gillessen-Kaesbach, and B. Horsthemke. 1992. Molecular diagnosis of the Prader-Willi and Angelman syndromes by detection of parent-of-origin specific DNA methylation in 15q11-13. Hum. Genet. 90: $313-315$.

Glenn, C.C., S. Saitoh, M.T. Jong, M.M. Filbrandt, U. Surti, D.J. Driscoll, and R.D. Nicholls. 1996. Gene structure, DNA methylation, and imprinted expression of the human SNRPN gene. Am. J. Hum. Genet. 58: $335-346$.

Holm, V.A., S.B. Cassidy, M.G. Butler, J.M. Hanchett, L.R. Greenswag, B.Y. Whitman, and F. Greenberg. 1993. Prader-Willi syndrome: Consensus diagnostic criteria. Pediatrics 91: 398-402.

Hurst, L.D., G. McVean, and T. Moore. 1996. Imprinted genes have few and small introns. Nature Genet. 12: $234-237$.

Leff, S.E., C.I. Brannan, M.L. Reed, T. Ozcelik, U. Francke, N.G. Copeland, and N.A. Jenkins. 1992. Maternal imprinting of the mouse Snrpn gene and conserved linkage homology with the Prader-Willi syndrome region. Nature Genet. 2: 259-264.

Mascari, M.J., W. Gottlieb, P.K. Rogan, M.G. Butler, D.A. Waller, J.A. Armour, A.J. Jeffreys, R.L. Ladda, and R.D. Nicholls. 1992. The frequency of uniparental disomy in Prader-Willi syndrome: Implications for molecular diagnosis. N. Engl. J. Med. 326: 1599-1607.

Nakao, M., J.S. Sutcliffe, B. Durtschi, A. Mutirangura, D.H. Ledbetter, and A.L. Beaudet. 1994. Imprinting analysis of three genes in the Prader-Willi/Angelman region: SNRPN, E6-associated protein, and PAR-2 (D15S225E). Hum. Mol. Genet. 3: 309-315.
Nicholls, R.D., J.H.M. Knoll, M.G. Butler, S. Karam, and M. Lalande. 1989. Genetic imprinting suggested by maternal heterodisomy in non-deletion Prader-Willi syndrome. Nature 342: 281-285.

Ozcelik, T., S. Leff, W.P. Robinson, T. Donlon, M. Lalande, E. Sanjines, A. Schinzel, and U. Francke. 1992. Small nuclear ribonucleoprotein polypeptide N (SNRPN), an expressed gene in the Prader-Willi syndrome critical region. Nature Genet. 2: 265-269.

Reed, M.L. and S.E. Leff. 1994. Maternal imprinting of human SNRPN, a gene deleted in Prader-Willi syndrome. Nature Genet. 6: 163-7.

Reis, A., B. Dittrich, V. Greger, K. Buiting, M. Lalande, G. Gillessen-Kaesbach, M. Anvret, and B. Horsthemke. 1994. Imprinting mutations suggested by abnormal methylation patterns in familial Angelman and Prader-Willi syndromes. Am. J. Hum. Genet. 54: 741-747.

Robinson, W.P., A. Bottani, Y. G. Xie, J. Balakrishman, F. Binkert, M. Machler, A. Prader, and A. Schinzel. 1991. Molecular, cytogenetic, and clinical investigations of Prader-Willi syndrome patients. Am. J. Hum. Genet. 49: 1219-1234.

Sutcliffe, J.S., M. Nakao, S. Christian, K.H. Orstavik, N. Tommerup, D.H. Ledbetter, and A.L. Beaudet. 1994. Deletions of a differentially methylated CpG island at the SNRPN gene define a putative imprinting control region. Nature Genet. 8: 52-58.

Wevrick, R., J.A. Kerns, and U. Francke. 1994. Identification of a novel paternally expressed gene in the Prader-Willi syndrome region. Hum. Mol. Genet. 3: $1877-1882$.

Received April 23, 1996; accepted in revised form June 10, 1996. 


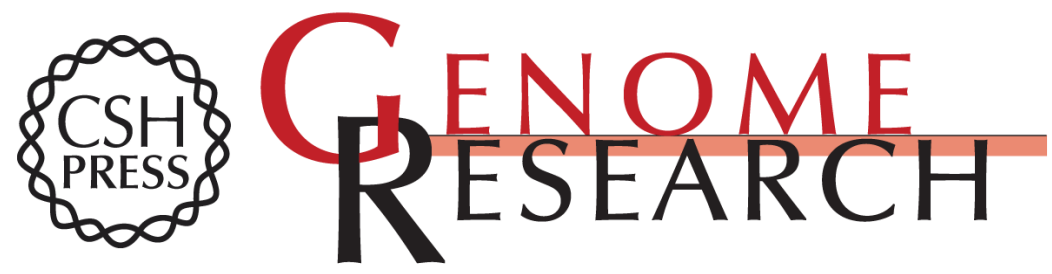

\section{Identification of a novel paternally expressed transcript adjacent to snRPN in the Prader-Willi syndrome critical region.}

Y Ning, A Roschke, S L Christian, et al.

Genome Res. 1996 6: 742-746

Access the most recent version at doi:10.1101/gr.6.8.742

\section{License}

Email Alerting

Receive free email alerts when new articles cite this article - sign up in the box at the Service top right corner of the article or click here.

\section{Affordable, Accurate Sequencing.}

